Monatsschrift f. Geburtshülfe u. Gynäkologie 1913;38:601-602

\title{
Friedrich Ahlfeld
}

Zum 16. Oktober 1913

An diesemTage hat der Emeritus von Marburg seinen 70. Geburtstag gefeiert. Wir machen uns zuversichtlich zum Dolmetscher der Emp-findungen unseies Leserkreises, indem wir ihm aus diesem Anlaß unsere herzlichen Glückwünsche aussprechen!

In Alsleben (Sachsen) geboren, hat Ahlfeld in Greifswald und Leipzig studiert. - \pm sa,ch der Approbation war er 1868-1873 Assistent von Gredé. 1873 in Leipzig habilitiert, wurde er nach 3 Jahren dort Prof, extra-ordinarius und Hebammenlehrer. Am 1. April 1881 ging Ahlfeld als 1\%ochfolger Kehrers nach Gießen, 1883 als Nachfolger Dohrns nach Marburg. 1907 legte Ahlfeld aus Gesundheitsrücksichten sein klinisch.es Amt nieder. Er hat sich in der Stadt seines langjährigen Wirkens nieder-gelassen und erfreut sich jetzt, wie wir zu unserer aufrichtigen Freude hören, nach einer so langen unermüdeten Tätigkeit als Lehrer, Forscher und Praktiker eines durchaus befriedigenden Wohlbefindens in seinem Marburger Tuskulum!

Ahlfeld ist der zweite Akademiker aus Gredés Schule: bis auf Sänger ist es ihm und uns beschieden, seine Mitschüler Schatz und Fehlíng noch unter uns zxi begrüßen.

Ahlfeld hat an seinem Teil überaus nachhaltig auf dem Gebiete der Geburtshülfe gewirkt und geschafft. Ein unermüdeter Lehrer seiner Studenten und Hebammen, hat er diesen ein vortreffliches Lehrbuch gegeben, das er in rasch aufeinanderfolgenden Auflagen auf der Höhe des Fortschrittes unseres Faches hielt.

Hat Ahlfeld auf den verschiedensten Gebieten der Geburtskunde, besonders auf dem der Mißbildungen abschließende Arbeit getan, so hat er ganz vornehmlich auf zweien überaus bedeutungsvolle An-regung gegeben und bis aus diese Tage in frohem Kampfesmut ver-treten: in der Desinfektionsfrage und in derjenigen der Selbstinfektion. In dem sich fast überstürzenden Entwicklungsgang unseres Faches hat Ahlfeld durch seine Stellungnahme in diesen beiden unbestritten überaus bedeutungsvollen Fragen sich auch auf den Diskussionsgebieten, die heute noch der Tummelplatz eifrigster Forschungen sind, eine achtunggebietende Stellung gesichert, an der die vorwärtsstürmende Jungmannschaft nicht vorübergehen darf. - Mcht unerwähnt clarf bleiben, daß Ahlfeld einer der ersten und energischsten Vertreter einer im Gegensatz zu seinem Lehrer Gredé maßvolleren Behandlung der Xachgeburtsperiode gewesen ist. Seine Anregungen auf dem Gebiete

$40^{*}$

602

Personalien.

der Beobachtung des Ungeborenen gelten noch für lange alien Ge-burtsforschern. Điese Tatsachen geben uns ein voiles Recht, dem ver-ehrten Kollegen und langjährigen Freund intimo ex corde unsere Glückwünsche zu diesem 70. Geburtstag darzubringen. Er hat erreicht, daß seine Arbeiten bis in die aktuellen Tagesfragen hinein reichen, daß sie ihm Anregung und sicher auch Befriedigung gewähren bis in hoffentlich noch recht feme ihm beschiedene Jahre! Quod felix faustumque sit!

A. Martin. 
Personalien.

Als Privatdozenten für Geburtshülfe und Gynäkologie haben sich niedergelassen: DDr. Bonäy und Heimann in Breslau, Dr. Stickel, Assistant der Kgl. Universitäts-Frauenklinik der Charité in Berlin, und DDr. Cwppellani und Poso in Neapel. 